\title{
Blade by Blade Tip Clearance Measurement
}

\author{
A. G. Sheard \\ Flakt Woods Limited, Axial Way, Colchester, Essex, CO4 5ZD, UK \\ Correspondence should be addressed to A. G. Sheard, geoff.sheard@flaktwoods.com
}

Received 31 December 2010; Accepted 20 June 2011

Academic Editor: Meinhard Taher Schobeiri

Copyright (C) 2011 A. G. Sheard. This is an open access article distributed under the Creative Commons Attribution License, which permits unrestricted use, distribution, and reproduction in any medium, provided the original work is properly cited.

This paper describes a capacitance-based tip clearance measurement system which engineers have used in the most demanding turbine test applications. The capacitance probe has survived extended use in a major European gas turbine manufacturer's hightemperature demonstrator unit, where it functioned reliably at a turbine entry temperature in excess of 1800 degrees Kelvin. This paper explores blade by blade tip clearance measurement techniques and examines probe performance under laboratory conditions in support of high-temperature installations. The paper outlines the blade by blade tip clearance measurement technique and describes the experimental facility used to study tip clearance measurement. The paper also fully describes the method used to calibrate the measurement system in order to ascertain measurement accuracy. The paper clarifies how the practical problems were overcome associated with making blade by blade tip clearance measurements in both compressor and turbine environments. Since its initial development, gas turbine development programmes have routinely used the clearance measurement system. The inherent robustness of the system has resulted in reliable in-service measurement of clearance in real world applications.

\section{Introduction}

This paper presents a study that the author initiated to demonstrate that a capacitance clearance measurement system utilising a frequency-modulated (FM) operating mode can make accurate tip clearance measurements over every blade in a compressor or turbine. Chivers [1] originally developed the FM capacitance probe to measure average tip clearance over a gas turbine compressor or turbine's blades. This paper reports the study results that established the accuracy with which Chivers' [1] tip clearance measurement system could make a blade by blade measurement of tip clearance in a laboratory environment.

Sheard et al. [2] developed an enhanced version of Chivers' [1] measurement system. Müller et al. [3] used the system to measure blade by blade tip clearance in the compressor and turbine of a BR700 development gas turbine. BMW and Rolls-Royce plc developed the Rolls-Royce BR700 family of engines through the joint venture company BMW Rolls-Royce to power regional and corporate jets.

Müller et al. [3] validated the blade by blade measurement of tip clearance by using the blade by blade measurement to calculate the average tip clearance and compared it with a measurement of minimum tip clearance using Sheard and Turner's [4] electromechanical clearance measurement system. Müller et al. [3] found the average tip clearance larger than the minimum clearance, Figure 1, a difference that they concluded was self consistent with the variation in the blade length they recorded during the gas turbine build plus the known bearing clearance.

Gill et al. [5] evaluated the Sheard et al. [2] and Chivers' [1] clearance measurement systems, fitting both to the stageone turbine of the same General Electric MS6001FA industrial gas turbine. Gill et al. [5] considered the MS6001FA stage-one turbine entry temperature proprietary. Despite commercial comments, Gill et al. [5] observed that the MS6001FA firing temperature was $1288^{\circ} \mathrm{C}$. Gill et al. [5] concluded that Sheard et al. [2] clearance measurement system was both viable in larger industrial gas turbines and more sensitive to clearance changes with better range than Chivers' [1] original measurement system.

Gill et al.'s [5] aim was to utilise the Sheard et al. [2] clearance measurement system in an active tip clearance control system utilising the capacitance probe that Lawrence and Sheard [6] designed and that Sheard [7] further refined. The closed loop active clearance measurement system modulated cooling air to cool or heat the turbine casing, causing it to shrink or expand; thus, maintaining a minimum safe gap 


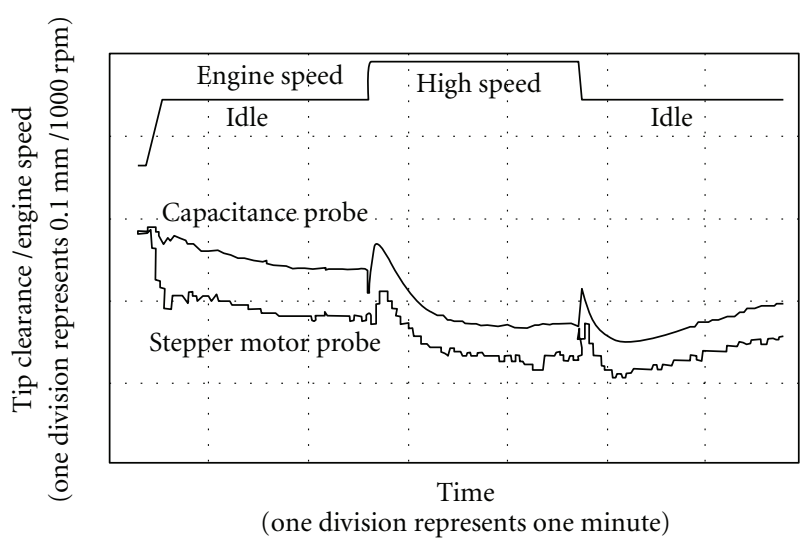

Figure 1: Trends in tip clearance. Measured by Müller et al. [3] using an electromechanical touch probe [4] and FM capacitance probe [2] in the high pressure turbine of a BMW Rolls-Royce $\mathrm{GmbH}$ BR700 development gas turbine.

between stage-one turbine blades and casing. Ramachandran and Conway [8] noted that a critical casing design feature was the optimisation of "thermal mass" size and location to minimise "ovalisation" of the casing as it heats from ambient to running temperature, facilitating the active control of turbine blade tip clearance.

This paper presents an extension of Chivers' [1] original measurement system required to, first, facilitate the measurement of clearance over every blade and, second, establish the accuracy with which one can make a blade by blade measurement of clearance. The experimental programme was conducted in a laboratory environment. The reader should, however, bear in mind that no changes were made to the capacitance probe that would affect its ability to withstand the environment in the high pressure turbine which Chivers [9] had already proven. Sheard [10] characterised the high pressure turbine environment and observed that a turbine entry temperature of $1200^{\circ} \mathrm{C}$ was representative of the turbine entry temperature of civil gas turbines at the time Chivers [9] conducted his research.

Chivers [1] first studied the variation in average tip clearances that occur as a consequence of internal gas turbine thermal effects using an FM capacitance probe. For the first time, Chivers [1] made continuous measurements of average tip clearance on a gas turbine compressor and turbine. Chivers' [1] results indicated that average tip clearance varied in two ways:

(1) low-frequency variations occur over an entire engine cycle due to thermal effects;

(2) high-frequency sinusoidal variations.

Chivers [9] attributed the high-frequency sinusoidal variations at the once per revolution frequency to bearing clearance. Chivers [9] was able to compensate for the effects of bearing clearance, identifying compressor disc and casing natural frequencies by fitting a total of four FM capacitance probes around a single compressor stage. By studying the phase relation between the outputs, he was able to identify disc and casing vibration modes. The maximum peak-topeak variation of average tip clearance measured at $0.1 \mathrm{~mm}$ when the gas turbine encountered a compressor disc or casing natural frequency, which the capacitance probe-based clearance measurement system was able to resolve.

There is extensive published material available on tip clearance measurement systems that can measure clearance over every blade in a compressor or turbine stage. The most commonly used technique is optical triangulation, as Drinkuth et al. [11], White [12], Baker et al. [13], Barranger and Ford [14], and Ford [15] describe. Optical clearance measurement systems work reliably in a manufacturing environment $[16,17]$. However, the complexity and physical size of these systems has historically made them difficult to install, and they have proven to be unreliable in high temperature and vibration environments such as those in a gas turbine.

The capacitance probe is an inherently rugged device and, therefore, has been the subject of study in the past. Barranger [18] described improvements to an FM type capacitance-based measurement system, utilising the capacitance probe-to-blade-tip capacitance in a resonant inductance, capacitance and resistance circuit (an oscillator). The oscillator's output frequency was a function of measured capacitance. The principal drawback of Barranger's [18] system was that the probe's connecting cable capacitance was typically two-magnitude orders greater than the 1 to 10 picofarad capacitance between probe and blade tip. Even relatively small temperature changes in the probe, and connecting cable resulted in a change in the capacitance readings, making a reliable measurement of average blade tip-to-casing clearance difficult.

Knoell et al. [19] developed a direct current- (DC-) polarised capacitance probe which used a guard electrode arrangement to minimise temperature effects. This system still suffered from temperature drift and, additionally, was only suitable for use in a compressor due to its susceptibility to "flame noise." The combustion process ionises combustion products leaving the combustor. Ionised gases are attracted to the electrically charged plate that comprises the front face of a direct current polarised capacitance probe. The ionised gases result is the sensor registering an unsteady electrical signal that it did not associate with any physical change in casing to blade tip gap size. The change in signal occurs as a consequence of the ionised combustion products, and constitutes unwanted noise, generally referred to as flame noise.

\section{FM Capacitance Probe Principle of Operation}

Chivers' [1] FM capacitance probe, unlike Barranger's [18] system, utilised a "driven screen" to overcome the problem of probe and connecting cable capacitance. The basic FM capacitance probe system, Figure 2, comprises a probe that incorporates an oscillator and guard amplifier and a ground station that incorporates a demodulator and RMS voltmeter. This RMS voltmeter provides an output voltage that relates to average tip clearance via a calibration. Chivers [1] describes 


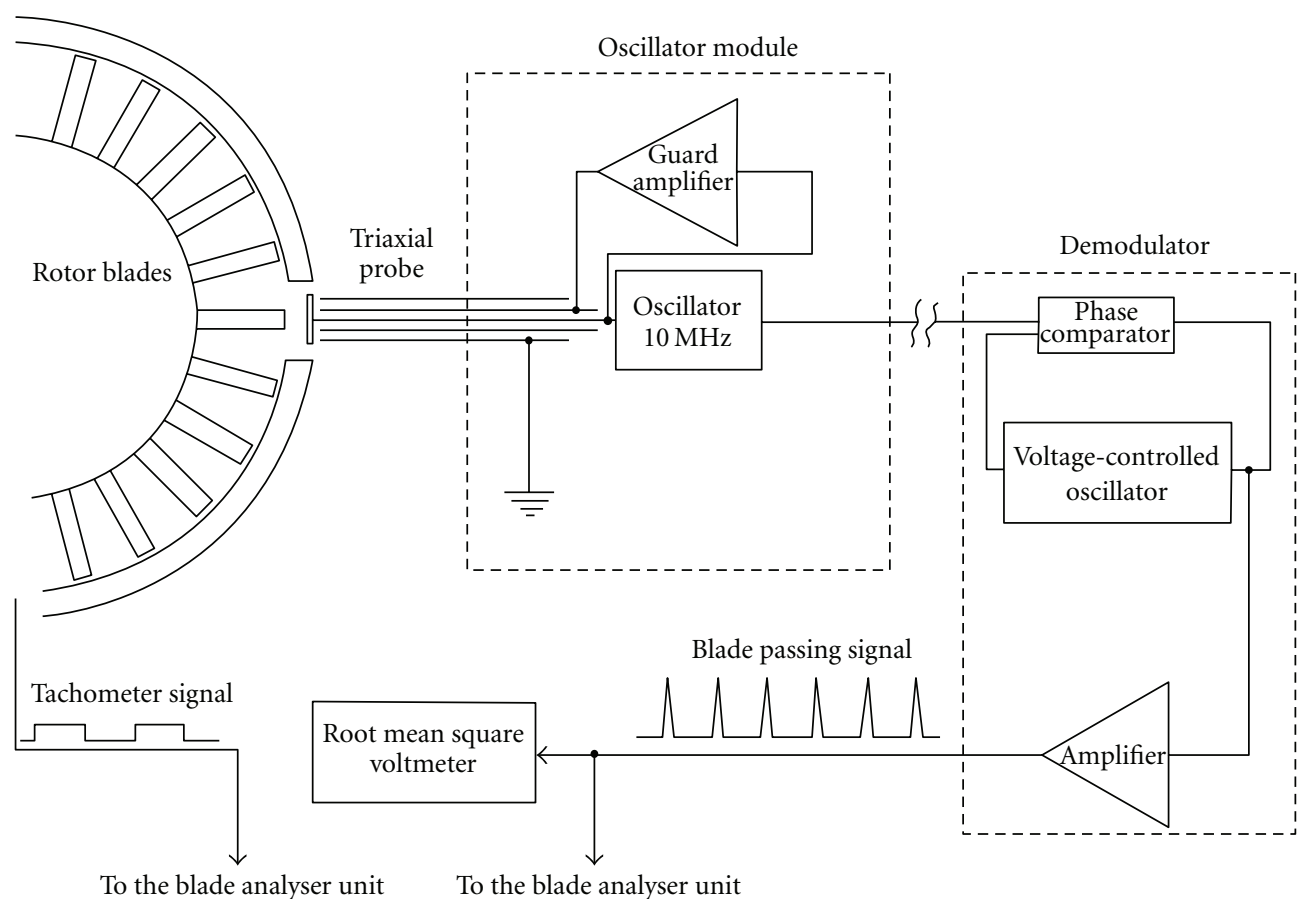

Figure 2: FM type capacitance tip clearance measurement system, schematic block diagram.

in detail the probe sensor, oscillator, and guard amplifier; thus, we will only touch upon them briefly here.

The probe sensor forms one plate of an oscillator's capacitor connected to the other components in the oscillator via the centre wire of a triaxial cable. The oscillator's function is to react to the change in capacitance that arises as a consequence of blade passing. The reaction takes the form of varying the oscillator output frequency so that it corresponds to the instantaneous capacitance measured at the probe tip. Chivers [1] chose a Hartly oscillator design operating at an optimum frequency of $10 \mathrm{MHz}$.

The guard amplifier's function is to ensure that the voltage between the inner screen of a triaxial cable and the centre wire is zero at all times, with the outer screen connected to ground. The reasoning is the origin of the probe and connecting cable capacitance, it is principally the capacitance of the cable. In order for capacitive charging of the inner screen to centre wire capacitor to occur, there must be a voltage difference between the two. By driving the inner screen of the triaxial cable to the same instantaneous voltage as the centre wire; the connecting cable capacitance is no longer a part of the capacitance measured between the probe sensor and blade tip. In practice, the guard amplifier comprises a unity gain amplifier capable of powering the reactive load represented by the total capacitance of the guard screen to ground.

Chivers' [1] original guard amplifier design was current limited. The maximum capacitive reactive load it could drive was $180 \mathrm{pF}$ at $10 \mathrm{MHz}$, equivalent to approximately $160 \mathrm{~mm}$ of mineral insulated cable. In the driven screen configuration, Chivers [1] cited a reduction in apparent capacitance from $180 \mathrm{pF}$ to $1.8 \mathrm{pF}$, with the capacitance between probe tip and blade varying from $1 \mathrm{pF}$ to $10 \mathrm{pF}$.
Sheard et al. [2] were able to develop Chivers' [1] original design, extending the maximum length of mineral-insulated cable that could be driven to five meters.

The ground station incorporated a demodulator unit comprised of a voltage controlled oscillator and a phase comparator. The output is an instantaneous voltage which is a function of frequency. Since the instantaneous value of frequency is a function of the capacitance between probe tip and blade, then the output voltage is a function of capacitance. The output from the demodulator unit is a pulse train, the peak height of each pulse a function of the capacitance between probe tip and each passing blade. During Chivers' [9] study, he fed the real time pulse train to an RMS voltmeter and an oscilloscope. He used the RMS voltmeter to measure the average clearance, and the oscilloscope to view the pulse train.

\section{The Blade Analyser Unit}

The objective of the current study was to measure clearance over every blade. This method required measuring the height of each pulse from the demodulator. A Blade Analyser Unit (BAU), Figure 3, originally developed by Killeen et al. [20], was used which comprises the following subsystems. The pulse train feeds into a peak detect, hold and reset circuit. This registers the height of the voltage peaks from the demodulator which then feed into an analogue to digital (A/D) converter. The pulse train and tachometer signal feed into a blade counter, which registers the blade number of the latest blade to pass. A dedicated microprocessor receives the output signals from the A/D converter and the blade counter.

The microprocessor acquires pulse heights from the A/D converter from one tachometer pulse to the next over one 


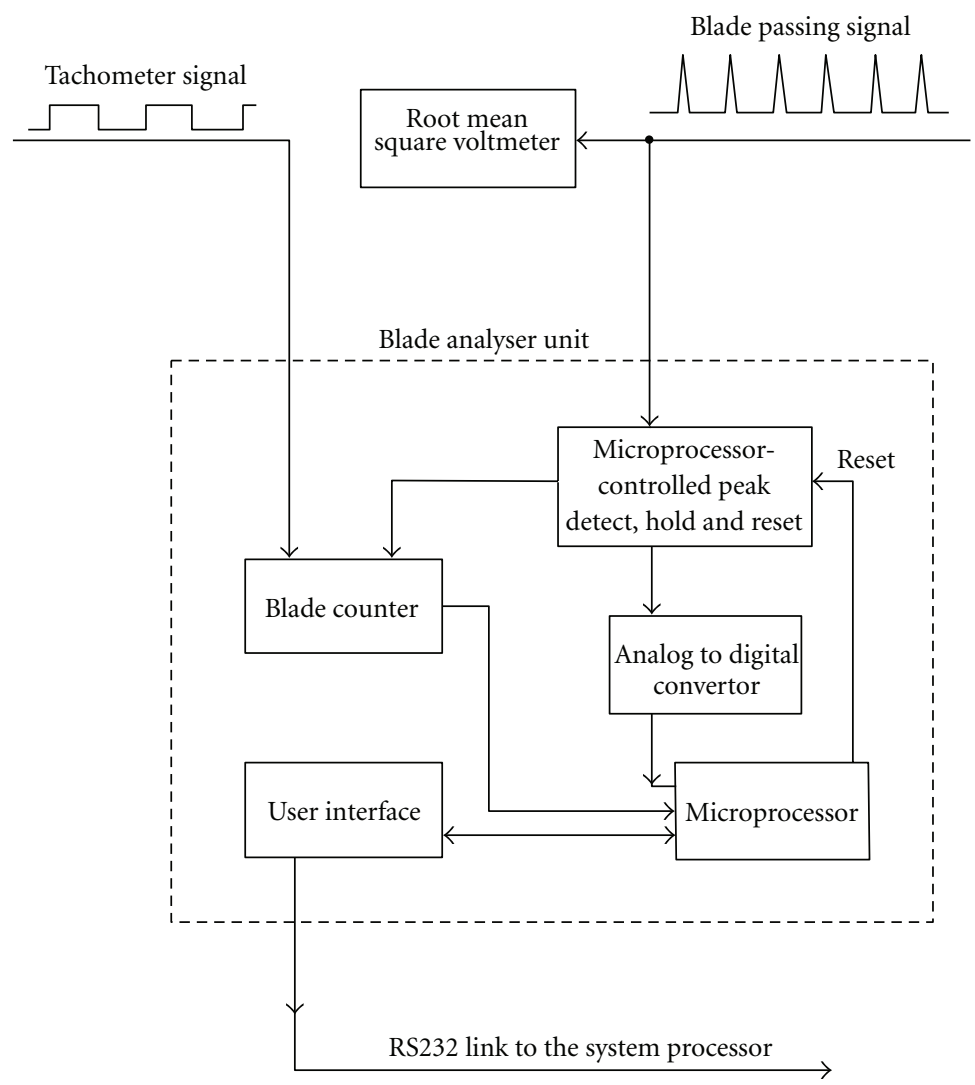

FIgURE 3: The blade analyser unit developed by Killeen et al. [20] and used to measure individual pulse heights, schematic block diagram.

complete revolution of the bladed disc. The microprocessor compares the number of pulses acquired with the known number of blades on the disc. If the two numbers are the same, it assumes no missed pulses, and the pulse heights pass to a user interface where they are output in RS-232 format as a string of blade numbers versus pulse height.

During the current study, the RS-232 output from the user interface feeds onto an 11-17 RS-232 to IEEE-488 converter to allow a Hewlett Packard computer, Figure 4, to read the output. Killeen et al. [20] wrote a software package to analyse the data from the BAU and the other inputs from the test facility.

\section{Facility Requirements}

The addition of the BAU to the basic FM capacitance probe provided a method of measuring the peak voltage out of the demodulator. Since the height of each peak was a function of clearance between each blade and the probe tip, the pulse heights may be related to tip clearance over each blade. In order to evaluate the accuracy of the blade by blade clearance measurement, a method was necessary to determine the clearance over each blade around a disc independent of the capacitance probe.

Second, there was a need for a calibration method for the capacitance probe. During his work, Chivers [9] observed not only that the probe/demodulator combination determined absolute clearance versus system output, but also was a function of geometry. In this context, Chivers [9] defined "geometry" effects as including fundamental physical factors which affect the absolute value of capacitance measured, such as measuring rotor blade tip thickness and the measuring probe sensor electrode area. Additionally, Chivers [9] found the angle of the blade tips to the engine axis (the stagger angle) and relative blade spacing (mark space ratio) to affect calibration.

The current study primarily establishes the absolute accuracy with which an FM capacitance probe could measure clearance over individual blades. In order to eliminate geometry and temperature effects, the facility design required an on-line calibration capability for the capacitance probe, so that one could perform a calibration immediately prior to measuring tip clearance.

\section{Facility Description}

A full compressor or turbine stage was not required for the laboratory study of FM capacitance probe performance. A small spinning rig was designed, Figure 5, comprising principally of an integral air motor and bladed wheel. The wheel geometry replicated that of a full scale compressor, whilst small enough to be driven by the available air supply, Table 1. Air motors are purely mechanical devices and do not generate the electrical noise one associates with the rotating coils and magnets of a large electric motor. 


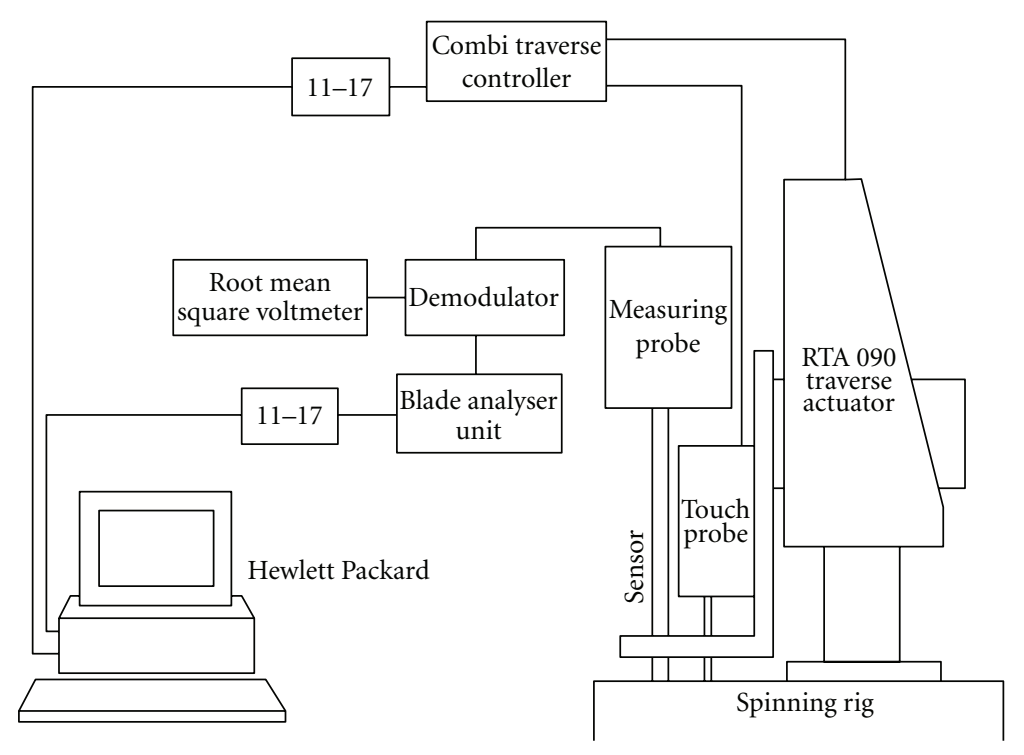

FIGURE 4: Layout diagram of the complete FM capacitance clearance measurement system used to measure clearance over every blade.

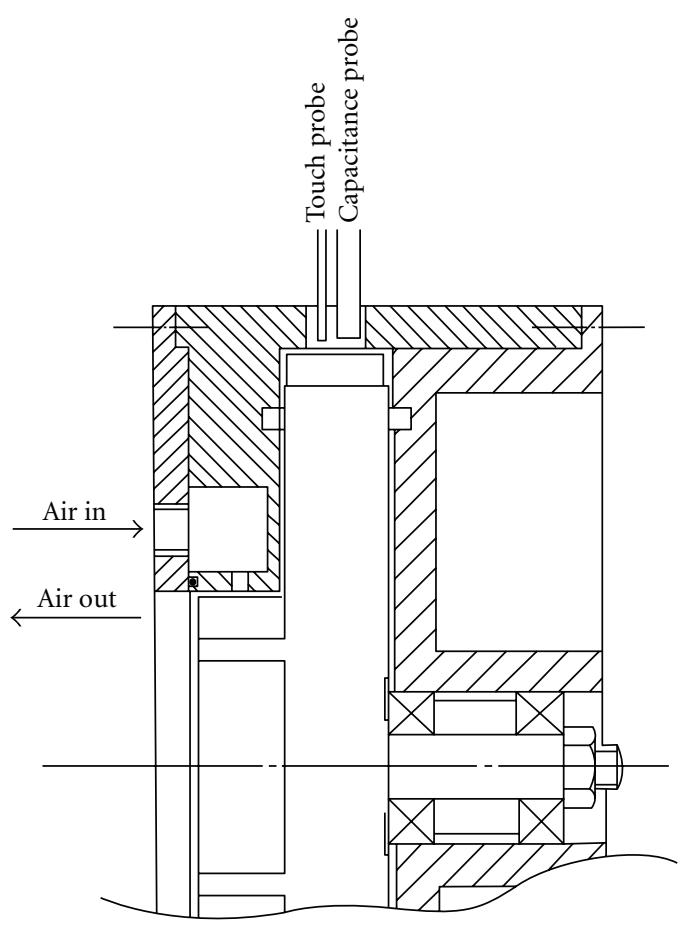

FIGURE 5: Spinning rig design used to evaluate the performance of the FM capacitance probe. The capacitance probe was mounted on a traverse actuator with touch probe to enable on-line calibration.

Calibration of the capacitance probe and measurement of clearance over every blade using a method other than the FM capacitance probe was achieved using a novel traverse-andtouch system. A traversing system was used, which Sheard et al. [21] describe in detail, as a platform on which to mount the capacitance probe. The traverse system comprises a precision stepper motor driven traverse actuator and active control system. Many others, notably Calvert et al. [22], have used the traverse system. Ginder [23] and Ginder et al. [24]
TABLE 1: Spinning rig wheel geometry.

\begin{tabular}{lc}
\hline Diameter & $204 \mathrm{~mm}$ \\
Number of blades & 24 \\
Blade material & Aluminium \\
Blade passing frequency @ 10,000 rpm & $4 \mathrm{KHz}$ \\
Blade stagger angle & Zero \\
Mark space ratio & 0.06 \\
Blade tip velocity @ 10,000 rpm & $107 \mathrm{~m} / \mathrm{s}$ \\
Blade tip thickness & $1.5 \mathrm{~mm}$ \\
Blade length & $12 \mathrm{~mm}$ \\
\hline
\end{tabular}

have used it to conduct area traverses behind every stator through a six-stage compressor at both design and off design conditions.

The ability to traverse the capacitance probe enables its position relative to the spinning rig's blades to vary by known amounts. The length of each blade on the wheel was cropped by known amounts relative to the longest blade, Table 2 . In order to "datum" the capacitance probe relative to the blades, it was necessary to establish its position relative to the longest blade. This was achieved by mounting a touch detection wire alongside the capacitance probe. Sheard and Turner [4] describe this method, so we will describe it only briefly here. One applies 400 volts to the wire which causes a discharge when the wire tip is within a small spark gap, typically a few microns. The touch occurs on the longest blade.

In the present study, the touch wire was mounted $0.1 \mathrm{~mm}$ radially inward from the capacitance probe, Figure 6 . When a touch was detected, the distance from the capacitance probe to the longest blade's tip was therefore $0.1 \mathrm{~mm}$. This revealed the length of each blade relative to the longest blade. Therefore, it facilitated calculation of the distance from the capacitance probe to every blade's tip. Further, when the traverse actuator stepped the capacitance probe back by a known amount, the clearance could still be calculated 
TABLE 2: Blade offset from the longest blade.

\begin{tabular}{lclc}
\hline Blade number & Offset $(\mathrm{mm})$ & Blade number & Offset $(\mathrm{mm})$ \\
\hline 1 & 0.0000 & 13 & 0.0334 \\
2 & 0.6888 & 14 & 0.6616 \\
3 & 0.0335 & 15 & 0.0827 \\
4 & 0.6436 & 16 & 0.6051 \\
5 & 0.1185 & 17 & 0.1289 \\
6 & 0.5788 & 18 & 0.5154 \\
7 & 0.1751 & 19 & 0.1706 \\
8 & 0.5197 & 20 & 0.4611 \\
9 & 0.2325 & 21 & 0.2347 \\
10 & 0.4661 & 22 & 0.4127 \\
11 & 0.3060 & 23 & 0.3076 \\
12 & 0.3837 & 24 & 0.3409 \\
\hline
\end{tabular}

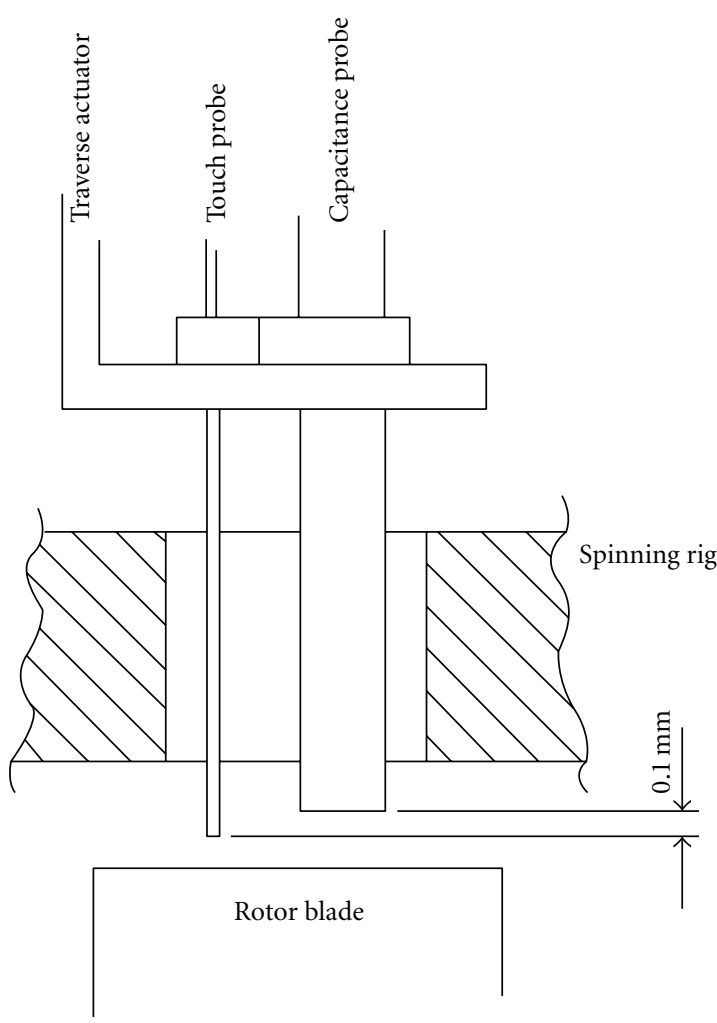

Figure 6: FM capacitance probe and touch wire mounting arrangement on the traverse actuator carrier.

between the capacitance probe and each blade. In this way, it was possible to calculate the clearance between capacitance probe and blade tip at all positions, following the "datuming" of the probe. The experimental programme used this process to derive the known clearance.

The practical realisation of the spinning rig, Figure 7, vented the air motor exhaust directly into a sound proof test cell, with the traverse actuator mounted on top of the wheel housing. Figure 8 shows a close up of the capacitance and touch probes' clamping arrangement on the traverse actuator carrier.

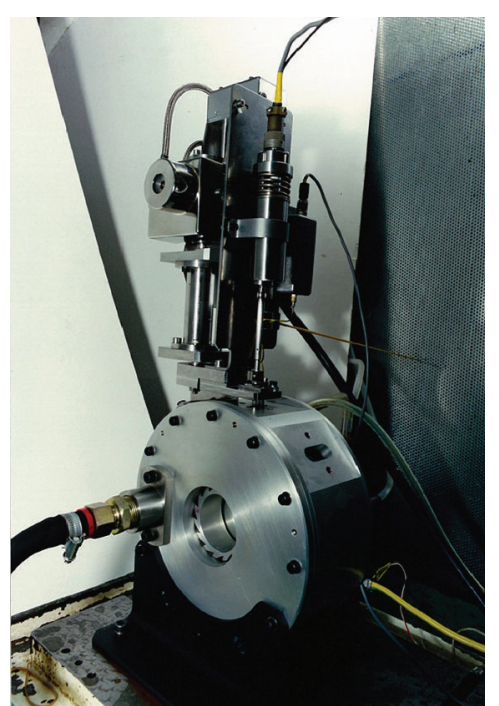

FIGURE 7: The spinning rig used to evaluate performance of the FM capacitance probe.

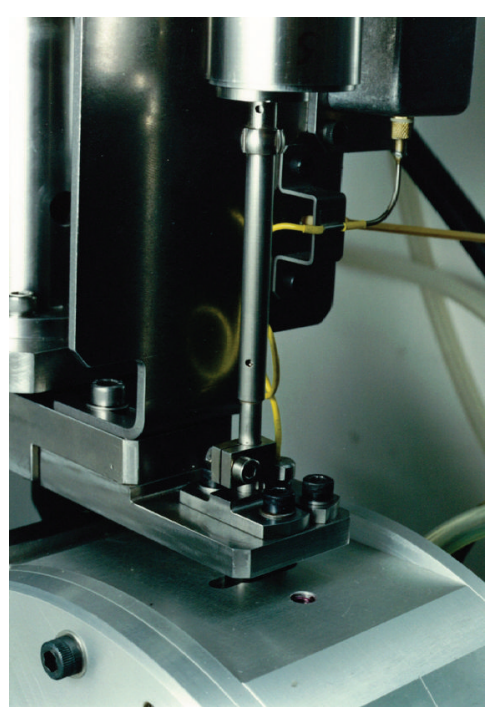

FIGURE 8: Close-up view of the traverse actuator mounting on the spinning rig housing showing the clamping arrangement of the FM capacitance probe and touch wire.

\section{Experimental Programme}

The experimental programme fell broadly into two phases: (1) commissioning of the spinning rig and BAU and (2) establishing the accuracy with which the capacitance probe could measure clearance over individual blades.

The spinning rig and BAU were commissioned at $10,000 \mathrm{rpm}$, the maximum speed at which continuous operation of the spinning rig was possible due to air supply limitations. The blade passing frequency at 10,000 rpm was $4 \mathrm{KHz}$, considered high enough to be representative of the blade passing frequency of a typical compressor or turbine. The capacitance probe drove in towards the spinning rig blades until the wire registered a touch. The capacitance probe's position was then calculated relative to 


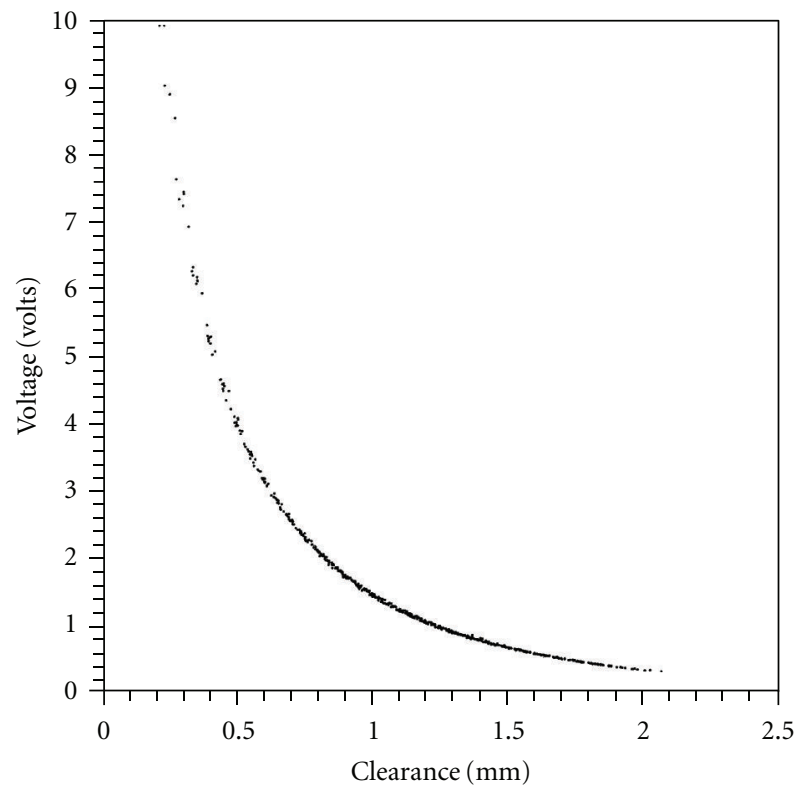

FIGURE 9: FM capacitance probe output plotted against known clearance illustrating the one over distance nature of the capacitance probe output. Each dot on the graph is a single measurement made over a single blade.

every blade, and independently the BAU was used to record the capacitance probe output for each blade. The capacitance probe was then stepped back $0.1 \mathrm{~mm}$ using the traverse actuator, and recorded BAU output again. This procedure was repeated twenty times, increasing clearance over the longest blade to $2.10 \mathrm{~mm}$, plotting the known clearance over each blade against the capacitance probe output, Figure 9 .

A least squares technique was used to fit a "one over" distance curve through the data. Calibration error was determined by subtracting known clearance from that obtained using the calibration which was plotted against clearance, Figure 10. The result indicated that the calibration gave clearance over each blade to an accuracy of $\pm 0.025 \mathrm{~mm}$ over a $2.0 \mathrm{~mm}$ range. Whilst this error was comparable to Chivers' [9] observations, the author hoped that datuming the capacitance probe against a wheel of known geometry would eliminate many of the factors that contributed to Chivers' [9] overall error.

At short range, measuring small clearances, the sensitivity of a capacitance probe is high. As clearance increases sensitivity reduces, until at a range of $2.0 \mathrm{~mm}$ there is virtually no change in probe output with change in clearance. We might reasonably expect this phenomenon to give results of rising error with increasing clearance. This result was not seen (see Figure 10). The error was replotted against the blade number as Figure 11 illustrates. There was a clear sinusoidal variation of the blade to blade results. The wheel was checked with a dial gauge. The wheel was running $\pm 0.025 \mathrm{~mm}$ eccentrically in its bearings which was contributing to the capacitance probe error.

The data reduction software was modified to calculate each blade's offset due to bearing eccentricity and subtracted it from each measurement, eliminating the effect of bearings

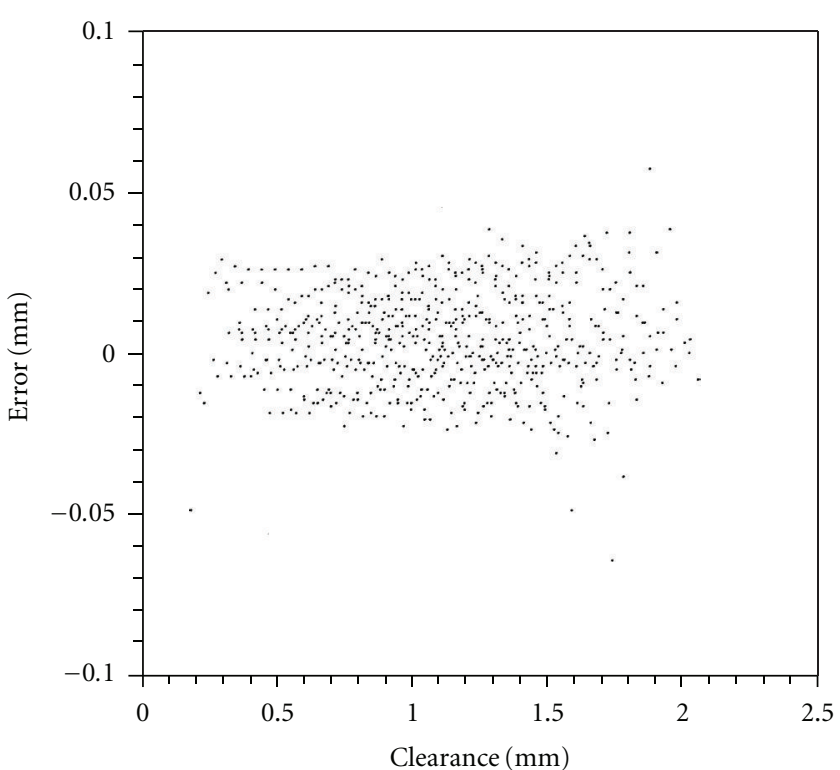

FIGURE 10: Error in FM capacitance probe measurement, calculated by subtracting the known clearance between probe and blade tip from that obtained using the probe calibration for each blade.

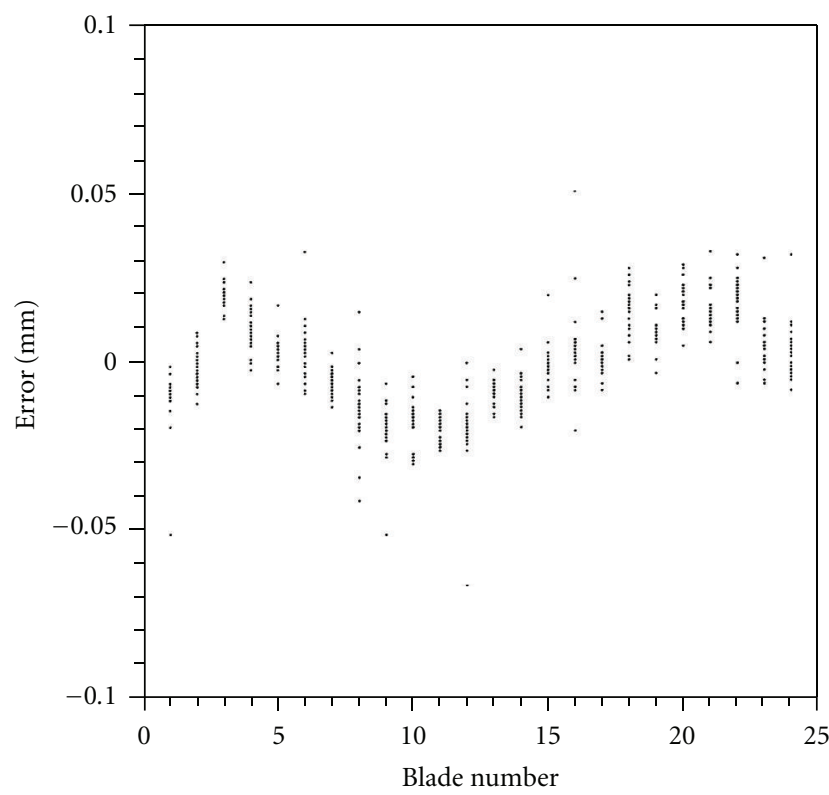

FIGURE 11: Error in FM capacitance probe measurements plotted against blade number around the spinning rig wheel, illustrating a $+1 /-0.025 \mathrm{~mm}$ variation in blade height due to shaft eccentricity.

from the error, Figure 12. The corrected clearance was plotted against known clearance, Figure 13, with noticeably less scatter. Error against clearance was then replotted, Figure 14, exhibiting the expected trend of increasing error with increasing clearance. The trend in error was as expected, with an accuracy of $\pm 0.01 \mathrm{~mm}$ over the first millimetre of the probe's range. The commissioning of the spinning rig and BAU was concluded to be complete and, therefore, the second phase of experimental work could commence. 


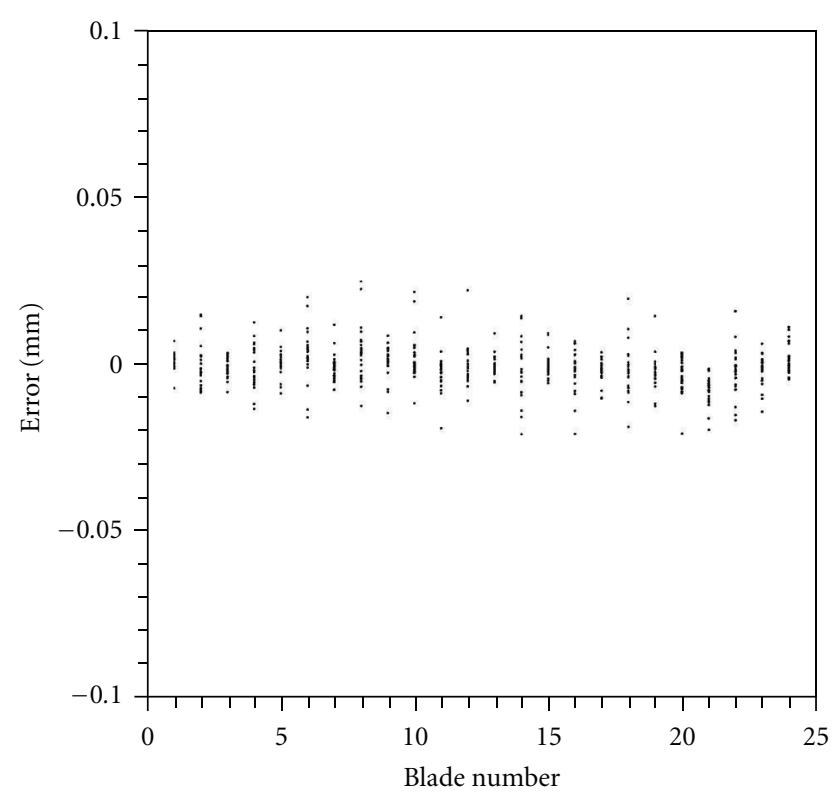

FIGURE 12: Error in FM capacitance probe measurements plotted against blade number around the spinning rig wheel after compensating the error due to shaft eccentricity.

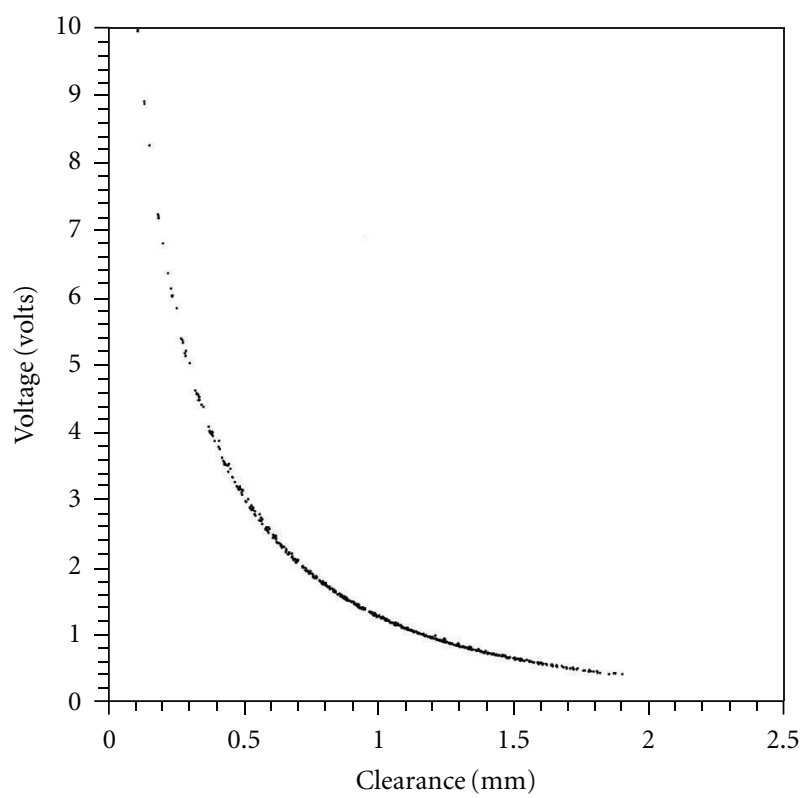

FIGURE 13: FM capacitance probe output plotted against known clearance after compensating for shaft eccentricity.

The primary difference between an engine test and the spinning rig is that one does not know the length of each blade relative to the longest blade. Second, datuming of the capacitance probe with a touch wire assumes blade conductivity, which may not be the case with ceramic or thermal barrier coated blades. An experimental programme was devised to calibrate the capacitance probe and then measure clearance over each blade without touching the longest blade or knowing the length of each blade relative to it. The following method was used. The spinning rig

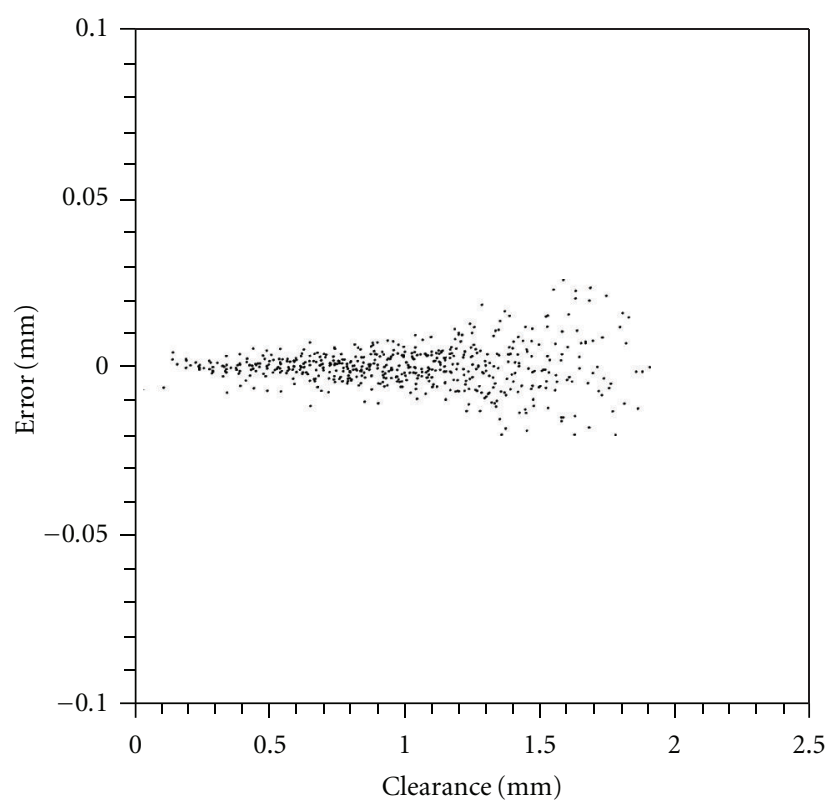

FIGURE 14: Error in FM capacitance probe measurement calculated after compensating for bearing eccentricity.

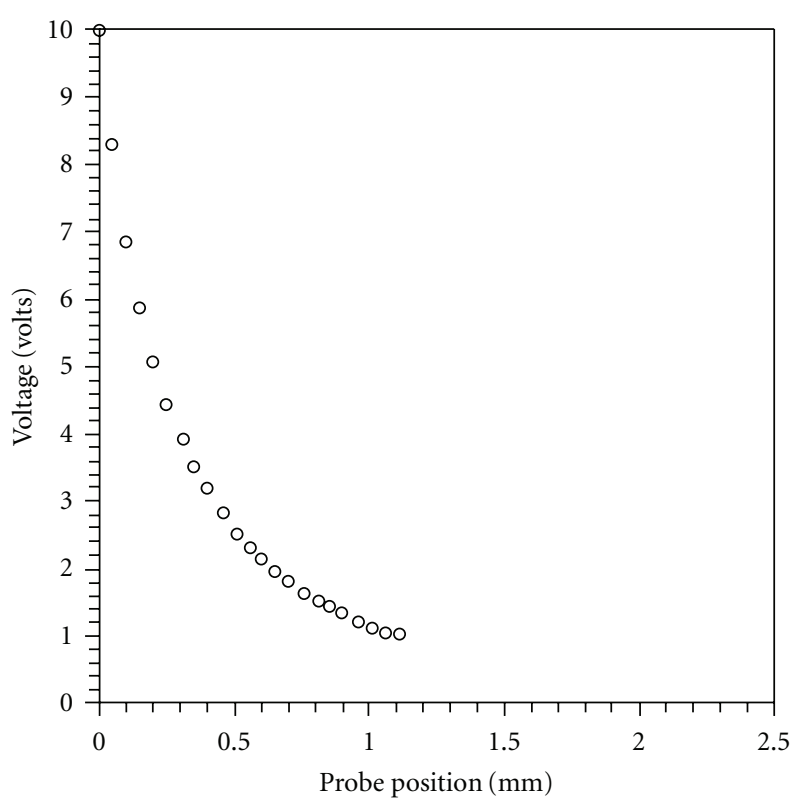

FIGURE 15: FM capacitance probe output for the longest blade of the spinning rig wheel plotted against known position, which was changed using the traverse actuator.

speed was stabilised at 10,000 rpm, and the traverse actuator moved in until the capacitance probe was close to the longest blade, but not touching. The reading from the BAU for the longest blade was then recorded and the traverse actuator then used to step the probe out $0.05 \mathrm{~mm}$ before repeating the data acquisition process. Probe output was then plotted against position, Figure 15, assuming zero clearance between capacitance probe and blade tip for the first data point. 


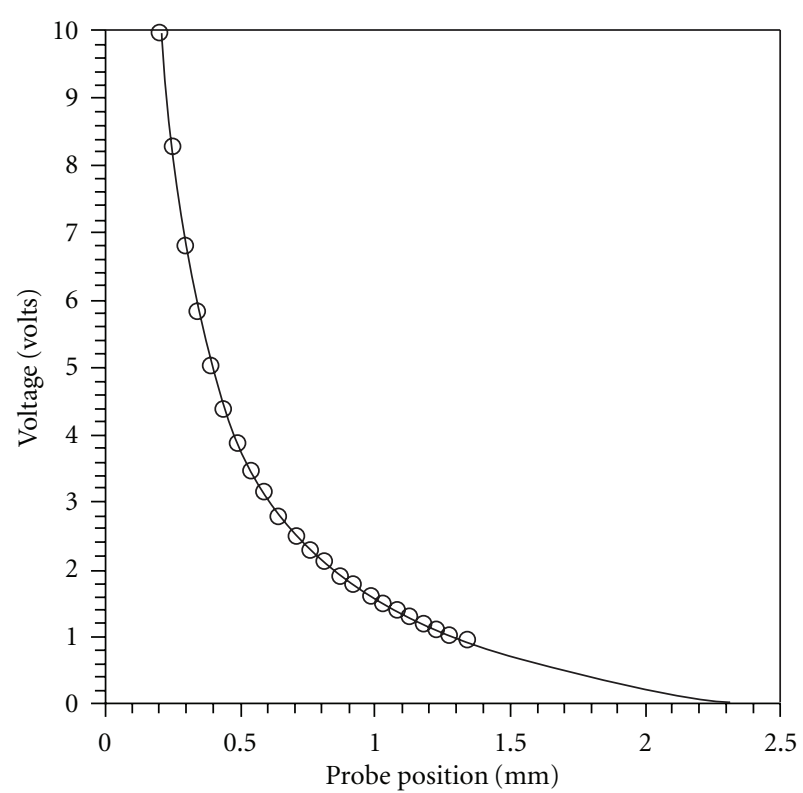

FIGURE 16: FM capacitance probe calibration obtained without datuming the probe or knowing the length of each blade relative to the longest blade. The figure also shows the actual position of the data points used in the calibration.

A least squares technique was used to fit a curve through the data in Figure 15, assuming an equation of the form:

$$
V=A 1+\frac{A 2}{D},
$$

where $A 1$ and $A 2$ are constants determined by the curve fit, $D$ is the distance between capacitance probe and blade tip in millimetres, and $V$ is capacitance probe output in volts. The physics of a capacitor dictate that capacitance should approach infinity as the distance between the capacitor plates' approaches zero. In this case, because of the unknown actual clearance, the first data point in Figure 15 was placed at zero. The negative value at which the curve tended to infinity was assumed as the unknown clearance between the first data point and the longest blade. Therefore, the sign of the constant $A 1$ was changed from negative to positive to give the actual calibration.

The actual position of each data point was found by datuming the capacitance probe immediately following the experiment. The actual data points match the calibration curve closely, Figure 16, giving confidence in the method used to calibrate the capacitance probe without touching the longest blade or knowing the length of each blade relative to the longest blade.

Once a calibration had been obtained, the BAU was used to acquire probe output pulse height for every blade. Knowing the length of each blade relative to the longest blade, it was once again possible to plot the known clearance over each blade against probe output, Figure 17. This figure shows known clearance plus the previously acquired calibration curve, illustrating the excellent agreement between the two. The error was calculated by applying the calibration to probe output voltage, then subtracting known clearance. The

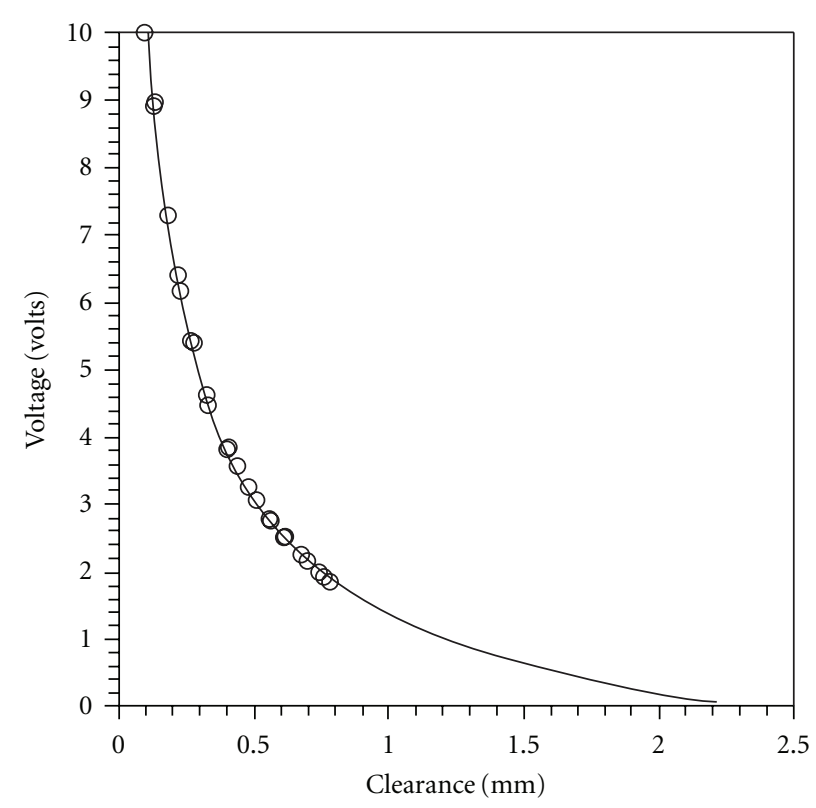

Figure 17: FM capacitance probe output for each blade of the spinning rig wheel plotted against known clearance, over plotted with the recently acquired calibration.

resulting error plot, Figure 18, had only twenty four points, each corresponding to the error in clearance over one of the spinning rig wheel blades. The clearance was measured without knowledge of the probe's initial position relative to the longest blade and without knowledge of the length of each blade relative to the longest blade.

The error of $\pm 0.025 \mathrm{~mm}$, Figure 18, is sufficiently low for the approach to blade by blade measurement of clearance to give useful data as part of a gas turbine development programme. Both the capacitance probe and stepper motor probe had been used as separate measurement systems in a BR700 development gas turbine [3]. As such, a "hybrid" unit combining the two clearance measurement systems and a traverse actuator into a single system had the potential to be successfully applied to both gas turbine development engine compressor and turbine environments.

\section{Further Development}

Sheard et al. [25] further refined the FM capacitance probe system calibration method that this paper describes. Sheard and Killeen [26] then combined the capacitance probe, touch probe, and traverse actuator into single hybrid unit, Figure 19, to develop a capacitance probe that one can calibrate on line. The prototype unit incorporates a $6 \mathrm{~mm}$ stroke traverse actuator.

Sheard and Killeen [27] then evaluated the prototype unit in a compressor test rig, fitting the prototype unit of Sheard and Killeen's [26] to the final stage of the compressor rig. As with the work in this paper's study, Sheard and Killeen [27] identified that the rotor was running eccentric, in this case $\pm 0.050 \mathrm{~mm}$. Sheard and Killeen [27] concluded that this level of eccentricity was self-consistent with the 


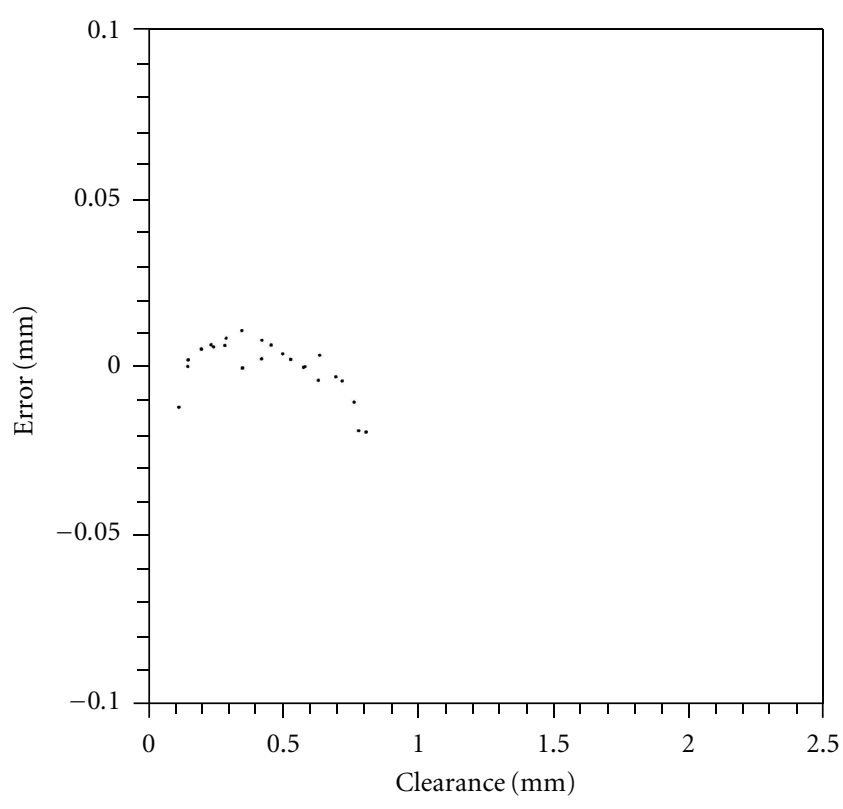

FIGURE 18: Error in FM capacitance probe measurement over the twenty four blades around the spinning rig wheel calculated by subtracting the known clearance between probe and blade tip from that calculated from the capacitance probe calibration. The calibration was obtained without datuming the capacitance probe.

$0.075 \mathrm{~mm}$ design clearance in the bearings. Sheard and Killeen [27] successfully made a blade by blade tip clearance measurement. They also measured the clearance over the longest blade around the compressor using Sheard and Turner's [4] stepper motor probe. The measurement was in close agreement to the measurement of tip clearance over the longest blade made using Sheard and Killeen's [26] prototype, and hence the author judged the blade by blade measurement system a success.

Although the blade by blade measurement system was successful, the reader should bear in mind that a capacitive approach to blade by blade clearance measurement is just one approach and has its limitations. As previously mentioned in this paper, ionised combustion products leaving the combustor result in flame noise. Flame noise may be regarded as an unsteady error source. A second limitation is the blades' axial thermal movement relative to the casing in which they run. Blades have an aerofoil shape and over the course of an engine cycle they move axially relative to their casing. A capacitance probe mounted in that casing, at different times during an engine cycle, will form a capacitive couple with a different part of the blade. Parts of the blade have a different cross-sectional area as a consequence of blade geometry. A change in a probe's axial location relative to blades will therefore result in an apparent change in tip clearance which is a steady-state error source.

Engineers can avoid the above unsteady and steady-state error sources with optical clearance measurement systems, an approach that Kempe et al. [28] and Haffner et al. [29] favoured. In line with this paper's focus, Kempe et al. [28] and Haffner et al. [29] identified the benefits of online calibration of the measurement system when making a blade by blade measurement of clearance. Kempe et al. [30] described initial laboratory validation of the optical clearance measurement system and its application in an Alstom GT26 turbine's first stage behind each of the combustors. The GT26 utilises a sequential combustor system unique to the Alstom GT24 and GT26 gas turbines. The optical measurement system worked well initially; however, after six hours the signal to noise ratio fell too far to detect any tip clearance. Kempe et al. [30] attributed the degradation in signal to noise ratio to changes in the optical fibers' thermal behaviour within the casing and the turbine enclosure. As such, there is practical difficulty in reliably operating this optical clearance measurement system in the turbine environment.

Although the clearance measurement system presented in this paper was anticipated to find wide-spread application in a research environment where the tip clearance's blade by blade measurement was of primary interest, this was not the case. Some scholars used the clearance measurement system in research application, notably Lawson [31] and Lawson and Ivey [32]. They used the blade by blade measurement not to study tip clearance, but blade tip timing. The clearance measurement system, however, proved most valuable in development applications. Müller et al. [3] utilised the clearance measurement system during the development of the BR700 gas turbine using circumferentially opposed capacitance probes to establish the magnitude of tip clearance variation as changing engine speed caused the high-pressure compressor to pass through casing and rotating system natural frequencies. The primary value of the clearance measurements that Müller et al. [3] reported was, however, the resolution of transient changes in average tip clearance that occurred as a consequence of step changes in engine speed. Müller et al. [3] utilised this transient clearance measurement to establish the compressor casing's thermal time constants over each compressor stage.

The major achievement of the clearance measurement system described in this paper is that it does overcome the practical problems of making a blade by blade tip clearance measurement in both compressor and turbine environments. As the work of Kempe et al. [30] demonstrates, blade by blade tip clearance measurement in an actual turbine application is difficult. Since its initial development, engineers have used the Sheard et al. [2] clearance measurement system routinely in gas turbine development programmes. The inherent robustness of Lawrence and Sheard's [6] sensor concept, coupled with Sheard et al. [2] mineral-insulated cable and frequency-modulated electronics system, have proven both robust and reliable in service. However, the inherent limitations of a capacitive measurement system remain. Those limitations are both known and predictable and therefore ultimately manageable in real world applications.

\section{Conclusions}

(1) The capacitance probe studied is capable of measuring clearance over individual blades to an accuracy of $\pm 0.01 \mathrm{~mm}$ over a 0.0 to $1.0 \mathrm{~mm}$ range, and $\pm 0.025 \mathrm{~mm}$ over a 1.0 to $2.0 \mathrm{~mm}$ range. 


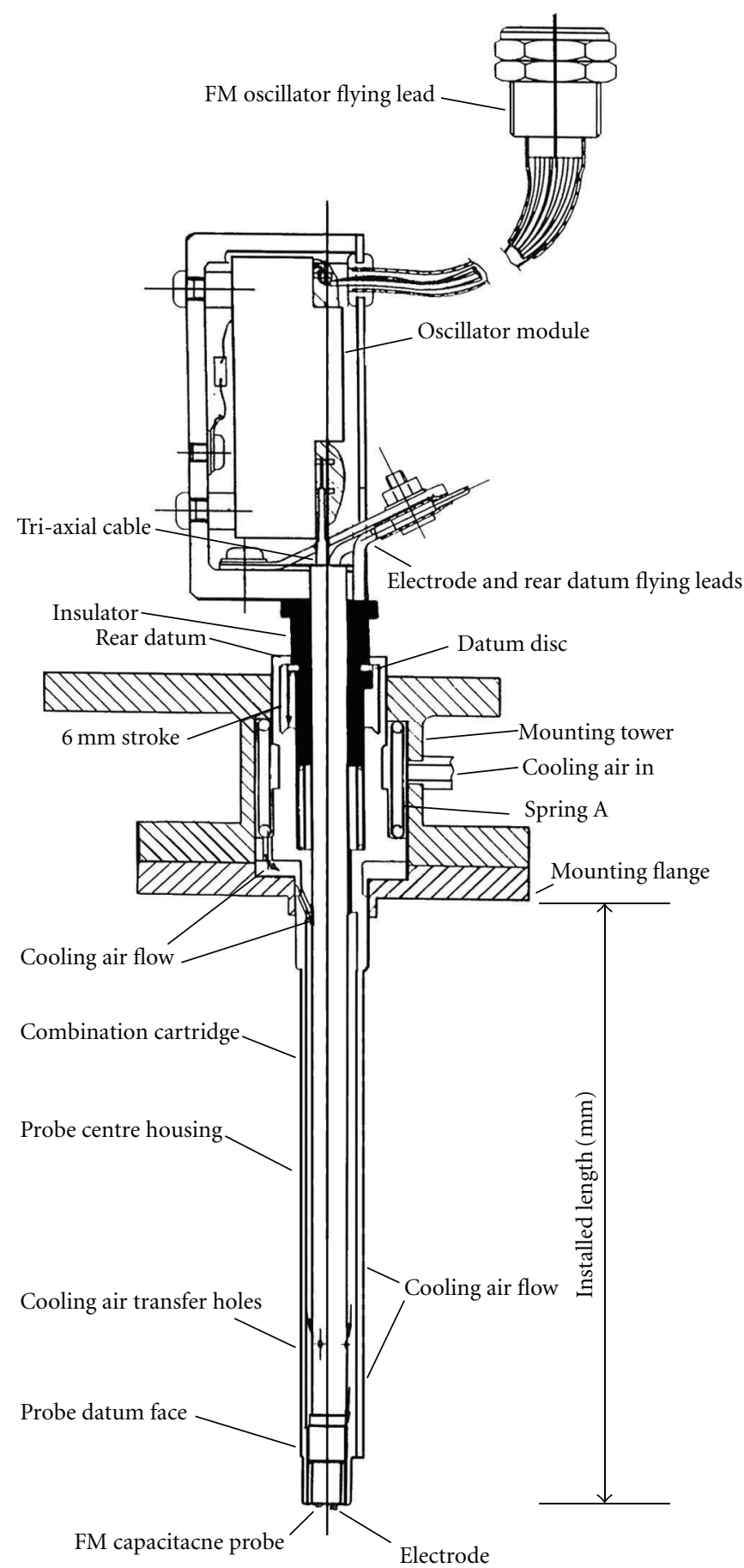

FIGURE 19: The hybrid probe developed by Sheard and Killeen [26] and used by Sheard and Killeen [27] to measure the blade by blade tip clearance in a high-pressure compressor rig.

(2) The capacitance probe studied measures clearance over individual blades to an accuracy of $\pm 0.025 \mathrm{~mm}$ when operated in a manner similar to that envisaged during operation in a gas turbine compressor or turbine installation.

(3) A method has been developed of calibrating the capacitance probe which enables calibration in situ immediately prior to use. This overcomes the classical problems with capacitance probes of geometryinduced errors, and drift with temperature.

(4) A blade analyser unit (BAU) originally developed by Killeen et al. [20] accurately measured the peak output voltage from the capacitance probe demodulator. This enables one to use the capacitance probe to measure clearance over every blade, as opposed to only an average value for all blades. 
(5) The study gives confidence that engineers can use capacitance probes on a gas turbine to measure clearance over every blade in a compressor or turbine stage. This will facilitate the identification of casing and turbine vibration modes, allow a more accurate calculation of average tip clearance, and enable engineers to identify the change in longest blade length following a casing rub.

\section{References}

[1] J. W. H. Chivers, A technique for the measurement of blade tip clearance in a gas turbine, Ph.D. thesis, University of London, London, UK, 1989.

[2] A. G. Sheard, S. G. O'Donnell, and J. F. Stringfellow, "High temperature proximity measurement in aero and industrial turbomachinery," Journal of Engineering for Gas Turbines and Power, vol. 121, no. 1, pp. 167-173, 1999.

[3] D. Müller, A. G. Sheard, S. Mozumdar, and E. Johann, "Capacitive measurement of compressor and turbine blade tip to casing running clearance," Journal of Engineering for Gas Turbines and Power, vol. 119, no. 4, pp. 877-884, 1997.

[4] A. G. Sheard and S. R. Turner, "An electromechanical measurement system for the study of blade tip-to-casing running clearances," in Proceedings of the 37th American Society of Mechanical Engineers Gas Turbine and Aeroengine Congress, Cologne, Germany, 1992.

[5] S. J. Gill, M. D. Ingallinera, and A. G. Sheard, "Turbine tipclearance measurement system evaluation in an industrial gas turbine," in Proceedings of the 42nd American Society of Mechanical Engineers Gas Turbine and Aeroengine Congress, Orlando, Fla, USA, June 1997.

[6] D. C. Lawrence and A. G. Sheard, "Gap measurement device," US Patent no. 5,760, 593, June 1998.

[7] A. G. Sheard, "Capacitive gap measurement device," UK Patent no. 2325305 B, April 2000.

[8] J. Ramachandran and M. C. Conway, "MS6001FA-An advanced technology 70-MW class $50 / 60 \mathrm{~Hz}$ gas turbine," in Proceedings of the 39th GE Turbine State-of-the-Art Technology Seminar, 1996, GER-3765B.

[9] J. W. H. Chivers, "A technique for the measurement of blade tip clearance in a gas turbine," AIAA Paper No. 89-2916, 1989.

[10] A. G. Sheard, Aerodynamic and mechanical performance of a high pressure turbine stage in a transient wind tunnel., D.Phil. thesis, University of Oxford, Oxford, UK, 1989.

[11] W. Drinkuth, W. G. Alwang, and R. House, "Laser proximity probes for the measurement of turbine blade running clearances," ISA AS1 74228, 1974.

[12] S. D. White, “Turbine tip clearance measurement," USARTLTR-77-47, 1977.

[13] L. C. Baker, G. E. Grady, and H. R. Mauch, "Turbine tip clearance measurement," USARTL-TR-78-4, 1978.

[14] J. P. Barranger and M. J. Ford, "Laser-optical blade tip clearance measurement systems," in Proceedings of the American Society of Mechanical Engineers Joint Fluids Engineering Gas Turbine Conference and Products Show, pp. 127-131, New Orleans, La, USA, March 1980.

[15] M. J. Ford, "Clearance measurement systems," NASA CR 159402, 1980.

[16] A. G. Sheard, "A system for measuring blade and stator radius during compressor build and overhaul," in Proceedings of the 9th International Turbomachinery Maintenance Congress, pp. 1-12, Amsterdam, The Netherlands, October 1993.

[17] A. G. Sheard, G. C. Westerman, B. Killeen, and M. Fitzpatrick, "High-speed capacitance-based system for gaging turbomachinery blading radius during the tip grind process," Journal of Engineering for Gas Turbines and Power, vol. 116, no. 1, pp. 243-249, 1994.

[18] J. Barranger, "An in-place recalibration technique to extend the temperature capability of capacitance-sensing rotor blade tip clearance measuring systems," in Proceedings of the Society of Automotive Engineers Aerospace Meeting, San Diego, Calif, USA, 1978.

[19] H. Knoell, K. Schedl, and G. Kappler, "Two advanced measuring techniques for the determination of rotor tip clearance during transient operation," in Proceedings of the Fifth International Symposium on Airbreathing Engines, Bangalore, India, 1981.

[20] B. Killeen, A. G. Sheard, and G. C. Westerman, "Blade by blade tip clearance measurement in aero and industrial turbomachinery," in Proceedings of the 37th ISA International Instrumentation Symposium, pp. 429-447, San Diego, Clif, USA, May 1991.

[21] A. G. Sheard, B. Killeen, and A. Palmer, "A miniature traverse actuator for mapping the flow field between gas turbine blade rows," in Proceedings of the IMechE Machine Actuators and Controls Seminar, pp. 1-11, London, UK, March 1993.

[22] W. J. Calvert, R. B. Ginder, I. R. I. McKenzie, and D. J. Way, "Performance of a highly-loaded HP compressor," in Proceedings of the 34th American Society of Mechanical Engineers Gas Turbine and Aeroengine Congress, Toronto, Canada, June 1989.

[23] R. B. Ginder, "Design and performance of advanced blading for a high speed HP compressor," in Proceedings of the 36th American Society of Mechanical Engineers Gas Turbine and Aeroengine Congress, Orlando, Fla, USA, June 1991.

[24] R. B. Ginder, A. J. Britton, W. J. Calvert, I. R. I. McKenzie, and J. M. Rarker, "Design of advanced blading for a high speed HP compressor using an S1-S2 flow calculation system," in Proceedings of the IMechE Conference on Turbomachinery, 1991.

[25] A. G. Sheard, G. C. Westerman, and B. Killeen, "Online calibration technique for improved blade by blade tip clearance measurement," in Proceedings of the 38th International Instrumentation Symposium, pp. 31-51, Las Vegas, Nev, USA, April 1992.

[26] A. G. Sheard and B. Killeen, "Hybrid system for high temperature tip clearance measurement," in Proceedings of the 39th International Instrumentation Symposium, pp. 379-394, Albuquerque, NM, USA, May 1993.

[27] A. G. Sheard and B. Killeen, "Blade-by-blade tip clearance measurement system for gas turbine applications," Journal of Engineering for Gas Turbines and Power, vol. 117, no. 2, pp. 326-331, 1995.

[28] A. Kempe, S. Schlamp, T. Rösgen, and K. Haffner, "Lowcoherence interferometric tip-clearance probe," Optics Letters, vol. 28, no. 15, pp. 1323-1325, 2003.

[29] K. Haffner, A. Kempe, T. Rösgen, and S. Schlamp, "Method and an apparatus for determining the clearance between a turbine casing and the tip of a moving turbine blade," US Patent no. 7,400,418, July 2008.

[30] A. Kempe, S. Schlamp, T. Rösgen, and K. Haffner, "Spatial and temporal high-resolution optical tip-clearance probe for harsh environments," in Proceedings of the 13th International 
Symposium on Applications of Laser Techniques to Fluid Mechanics, Lisbon, Portugal, June 2006.

[31] C. P. Lawson, Capacitance tip timing techniques in gas turbines, Ph.D. thesis, Cranfield University, 2003.

[32] C. P. Lawson and P. C. Ivey, "Tubomachinery blade vibration amplitude measurement through tip timing with capacitance tip clearance probes," Sensors and Actuators A, vol. 118, no. 1, pp. 14-24, 2005. 

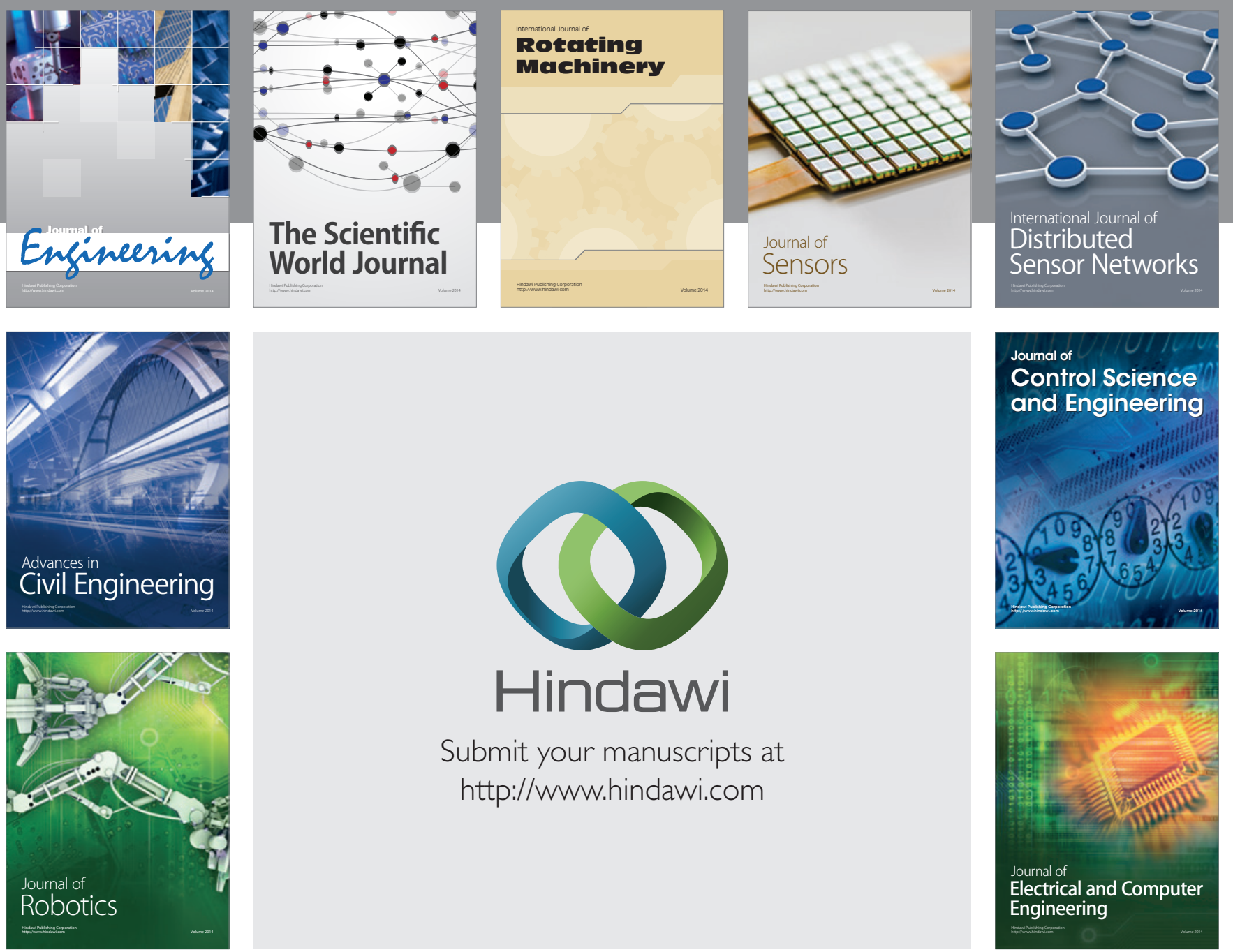

Submit your manuscripts at

http://www.hindawi.com
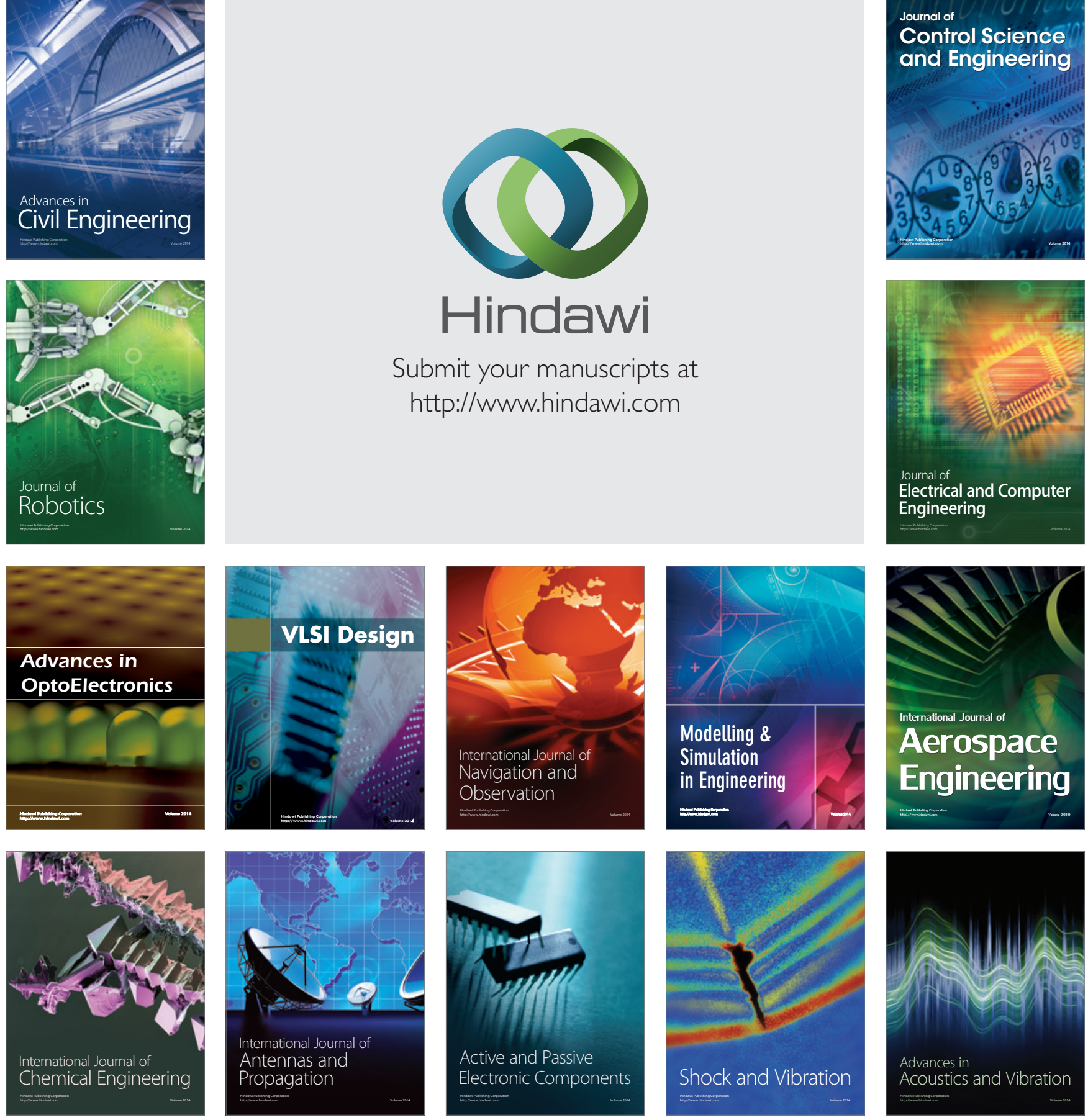